\title{
THE ELECTRORETINOGRAM IN GLAUCOMATOUS EYES*广
}

\author{
B Y \\ G. LEYDHECKER \\ From the Glaucoma Clinic, Institute of Ophthalmology, London
}

Sisce Du Bois-Reymond (1849) recorded the first action potential from an eye much work has been done on the subject. The most comprehensive treatment is that of Granit (194i), but the first clinical investigations were made by Karpe (1945). The reaction of the normal human dark-adapted eye when recorded by Karpe's technique is a single positive wave, corresponding to the $b$-wave (Granit), which here represents the reaction of the rods only. The height of a normal record varies between $0 \cdot 21$ and $0 \cdot 48 \mathrm{mV}$ (Karpe), and depends, among other things, on the amount of light reaching the retina. Karpe also described the reaction of human eyes in various diseases and discussed four electroretinogram records from glaucomatous eves, three with normal and one with subnormal $b$-wares. It is well known that in glaucoma the peripheral vision (that is, essentially, the rod vision) is often defective and it therefore seemed advisable to determine whether the electroretinogram (ERG) of the dark-adapted eye is influenced by defects in the visual field.

\section{Method}

Altogether 107 ERG is were obtained from 73 glaucomatous eyes in 34 patients. Fourteen eyes suffered from chronic simple and twenty from chronic congestive glaucoma. Five eyes were blind; in nine other cases vision had been so reduced that the patients were only able to perceive light or hand movements or to count fingers. The action potential was recorded with the apparatus and technique described by Karpe (1948), the earliest investigations being done under his direction. In most cases the stimulus was a light flash of 20 lux and ${ }_{2}^{1} 5$ sec. The patients were dark-adapted for 5 minutes before the stimulus was given. In most cases the size of the pupil of the dark-adapted eye was measured before the record was taken. A run of about ten recordings (one every quarter minute) was made. At the beginning and end of the run the apparatus was calibrated to $0.5 \mathrm{mV}$. For the evaluation of the curves the mean of all $b$-waves was taken. Because most of the patients were under treatment with pilocarpine or eserine drops it was found that in some cases the pupil was too small to allow the entrance of sufficient light to produce a maximal $b$-wave. In these cases the stimulus was increased to 80 lux. The ocular tension was measured before every experiment, and the visual acuity and fields of vision of all the patients were recorded. Patients with cataract were excluded. In almost every case it was possible to obtain records of both eyes at one session. Most of the patients easily learned to suppress blinking and eye movements which produce disturbing artefacts in the ERG. Beyond giving pantocaine drops, it was not necessary to use any kind of anaesthetic or sedative.

* Received for publication February 10, 1950.

t The expenses of this research were defrayed by the Alexander Pigott Wernher Memorial Trust. 


\section{Results}

In the ERGs (taken with a stimulus of 20 lux for $\frac{1}{25}$ sec.) from the 73 glaucomatous eyes, the recorded action potential of the retina varied between 0.09 and $0.44 \mathrm{mV}$.

The relationship between the visual field and the action potential is seen in Table I. The eyes are divided into four groups :

(a) Normal field;

(b) Loss of approximately half or less of the peripheral vision;

(c) Loss of more than half the peripheral vision;

(d) Blind eyes, including those in which the vision was reduced to counting fingers or hand movements.

TABLE I

Relationship between Height of b-wave and Extent of Visual Field

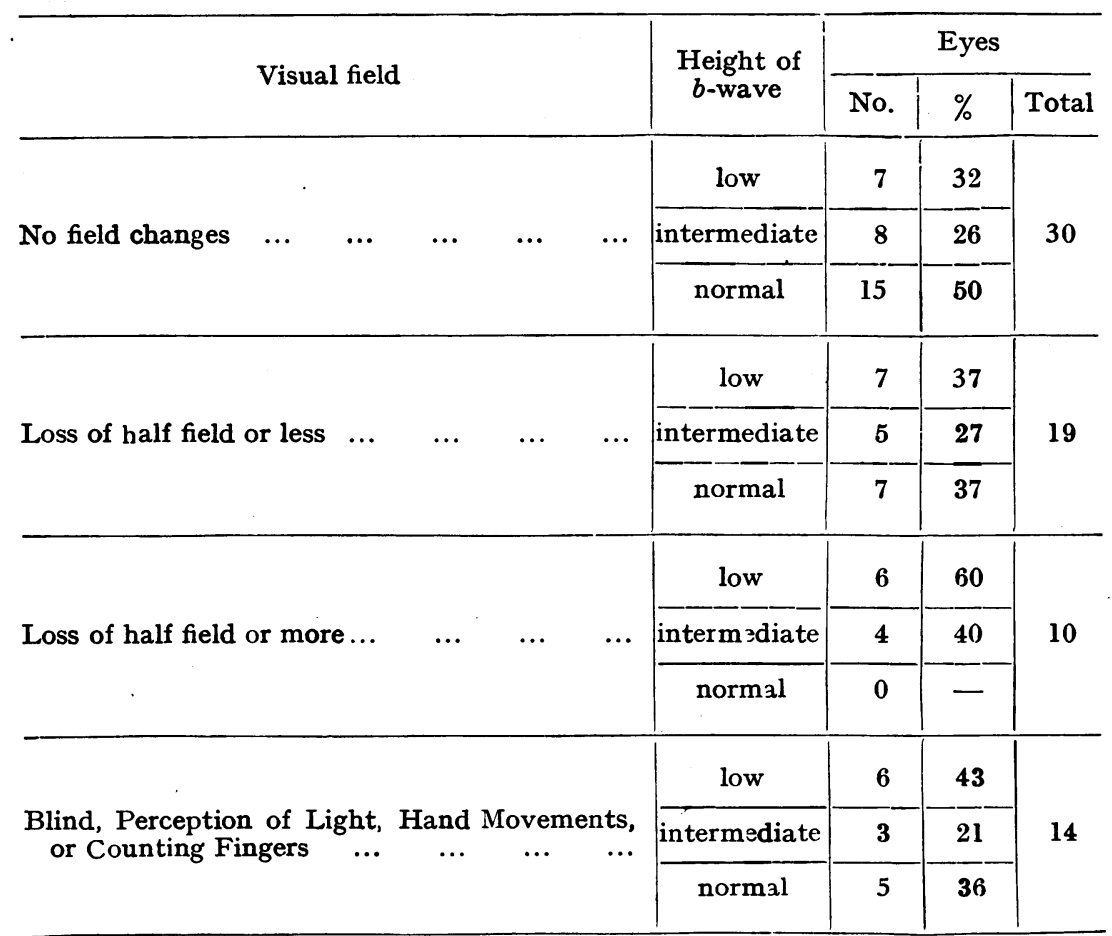

Eyes classified according to loss of peripheral field. Height of $b$-wave of ERG differentiated for each group thus:

Low (less than $0.23 \mathrm{mV}$ ). Intermediate $(0.23-0.30 \mathrm{mV}$ ). Normal (over $0.30 \mathrm{mV}$ ).

Stimulus was light flash of $20 \mathrm{lux}$ and $1 / 25 \mathrm{sec}$. 
When the records from the eyes with full vision and normal fields are compared with those from blind eyes, it is obrious that the extent of the visual field is of minor importance in determining the height of the $b$-wave. In eyes with a normal field (Group $a$ ) the percentage of low records (amplitude $<0.23 \mathrm{mV}$ ) was 23, whereas in blind eyes (Group $d$ ) it was no higher than 43 . Normal records $(>0.30 \mathrm{mV}$ ) were obtained in 50 per cent. of eyes with a normal field, and in 36 per cent. of blind eyes. When the same eyes were stimulated with 80 lux the percentage of normal curves increased in both groups; amongst the blind eyes normal records were obtained in 43 per cent., and low amplitude curves in 21 per cent.

Table II shows the same eyes grouped according to the diameter of the pupil. Those with a total iridectomy or a pupillary diameter of $4 \mathrm{~mm}$. or over gave normal $b$-waves in 65 per cent. and low values in 12 per cent. of cases. On the other hand, the reverse relationship was found in eyes with a pupillary diameter of less than $4 \mathrm{~mm}$. (normal $b$-waves-13 per cent., low-j6 per cent.). Amongst the eyes with a pupil of $4 \mathrm{~mm}$. or over, eight

TABLE II

Relationship between Height of b-wave and Pupil-Diameter

\begin{tabular}{|c|c|c|c|c|c|c|c|}
\hline & & & & Height of & & Eye & \\
\hline & 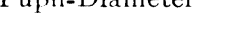 & & & $b$-wave & No. & $\%$ & Total \\
\hline & & & & low & 4 & 12 & \\
\hline $4 \mathrm{~mm}$. or more, & or large iridectomy & $\ldots$ & $\ldots$ & intermediate & 8 & 24 & 34 \\
\hline & & & & normal & 22 & 65 & \\
\hline & & & & low & 22 & 56 & \\
\hline 3-4 mm. or less & $\ldots$ & $\ldots$ & $\ldots$ & intermediate & 12 & 31 & 39 \\
\hline & & & & normal & 5 & 13 & \\
\hline
\end{tabular}

Eyes classified according to pupil diameter. Height of $b$-wave of ERG differentiated thus : Low (less than $0.23 \mathrm{mV}$ ). Intermediate $(0.23-0.30 \mathrm{mV}$ ). Normal (over $0.30 \mathrm{mV}$ ).

Stimulus was light flash of 20 lux and $1: 25 \mathrm{sec}$

were blind. In five of these a $b$-wave of $>0.30 \mathrm{mV}$ was obtained with a stimulus of 20 lux, and in six when the stimulus was 80 lux. The remaining three eyes gave an intermediate $b$-wave with 80 lux.

The ocular tension varied from $15-80 \mathrm{~mm}$. $\mathrm{Hg}$ (Schiötz) in all groups. There was no correlation between it and the magnitude 
of the ERG; neither was there any difference between the cases of chronic simple and chronic congestive glaucoma.

\section{Discussion}

These results show that field changes in glaucomatous eyes do not significantly influence the height of the $b$-wave in the ERG. Even in blind or almost blind eyes, normal $b$-waves were obtained. The stage of the disease and its type (congestive or simple), the ocular tension, the peripheral and central vision all appear not to influence the ERG. The height of the $b$-wave in eyes with a normal field and large pupils was not significantly greater than in blind eyes with large pupils. It is thus obvious that in glaucoma the same correlation exists between the diameter of the pupil and the height of the $b$-wave as that shown by Karpe for normal eyes. The ERG does not therefore provide a means of determining how much of the visual function remains in glaucoma.

These findings are consistent with our knowledge of the pathological changes which take place in the retina of glaucomatous eyes and with our theories of the origin of the action potential recorded in the ERG. In glaucoma the optic nerve fibres and ganglion cells degenerate while the remaining layers of the retina are little affected (Wolff, 1948). In this connection it is interesting that Karpe has described normal ERG records in cases of descending optic atrophy and has classified the atrophy in glaucoma with it; his findings are confirmed by the present investigation. It would seem to follow that since normal $b$-waves have been recorded in blind eyes with glaucomatous atrophy of the optic fibres, the retinal action potential must originate deeper than the ganglion cells. This view is consistent with that put forward by Bartley (1939), and Granit (1947), that the retinal process responsible for the $b$-wave is located in the bipolar layer.

\section{Summary}

ERGs were obtained from 73 dark-adapted glaucomatous eyes. The height of the $b$-wave, which indicates the response of the rods, ranged between 0.09 and $0.44 \mathrm{mV}$, the average being $0.267 \mathrm{mV}$ for a stimulus of 20 lux (normal value, $0.21-0.48 \mathrm{mV}$ ). The value. was higher when the pupil was large or when the stimulus was increased from 20 to 80 lux. There was no correlation with visual function and records of normal size were obtained from blind eyes. These results are consistent with the view that the action potential originates in the bipolar cell layer of the retina and is not therefore imparred in glaucomatous degenera- 
tion which affects the fibres of the optic nerve and the ganglion cells.

I am much indebted to Professor G. Karpe, of Stockholm, and Dr. Katharine Tansley, of the Institute of Ophthalmology, for help and guidance in this work.

\section{REFERENCES}

Bartley, S. H. (1939). Psychol. Rev., 46, 337.

Du BoIs-REymond, E. (1848-9). "Untersuchungen über thierische Elektricität" Berlin.

Granit, R. (1947). "Sensory Mechanisms of the Retina”. Oxford Univ. Press, London.

KARPE, G. (1945). Acta ophthal., Kbh., Suppl. 24.

(1948). Docum. ophthal., 2, 268.

Wolfr, E. (1948). "The Anatomy of the Eye and Orbit". 3rded. Lewis, London. 